\title{
Effect of cataract surgery on contrast sensitivity and quality of life in patients with different types of cataract
}

\section{Efecto de la cirugía de catarata en la sensibilidad al contraste y la calidad de vida de pacientes con diferentes tipos de catarata}

\author{
Valentina Berríos-Dolz¹, Patricia Chirinos-Saldaña1 and Rosa E. Adrianzén ${ }^{1,2 *}$ \\ ${ }^{1}$ Instituto Regional de Oftalmología Javier Servat Univazo; ${ }^{2}$ Universidad Nacional de Trujillo. Trujillo, Peru
}

\begin{abstract}
Objective: To determine the effect of cataract surgery on contrast sensitivity and quality of life of patients with different types of cataract. Methods: Prospective study with a preand post-test design in patients with indication for cataract surgery by phacoemulsification. Best-corrected visual acuity (BCVA) at different contrast levels and vision-related quality of life (V-RQOL) were evaluated before and 30 days after surgery. The study population was divided into 3 comparative groups according to the type of predominant cataract following the Lens Opacities Classification System III: nuclear, cortical and posterior subcapsular (PSC). Results: Seventy-eight eyes of 78 patients with a mean age of $69.3 \pm 9.6$ (51-86) years were included. In the preoperative period, low contrast sensitivity was slightly affected in the nuclear group and severely affected in the PSC group. V-RQOL limitations scale was significantly lower for the PSC group compared to the nuclear group (0 [0-15.6 vs. 6.2 [0-12.5; $p=0.040$ ). After surgery, BCVA and contrast sensitivity improved in the three study groups. The most significant changes were observed in the PSC group. V-RQOL improvement was positively related to visual acuity gain in high and low contrast in the three study groups. Conclusion: Cataract surgery significantly improved contrast sensitivity and quality of life of all patients, especially in those with PSC opacity.
\end{abstract}

Key words: Cataract. Visual acuity. Quality of life. Contrast sensitivity. Phacoemulsification. Surveys and questionnaires.

\section{Resumen}

Objetivo: Determinar el efecto de la cirugía de catarata en la sensibilidad al contraste y calidad de vida de pacientes con diferentes tipos de catarata. Métodos: Estudio prospectivo, con diseño pretest-postest en pacientes con indicación de cirugía de catarata por facoemulsificación. Se evaluó la agudeza visual mejor corregida (AVMC) a diferentes niveles de contraste y la calidad de vida relacionada con la visión (CVRV) antes y después de 30 días de la cirugía. La población se dividió en tres grupos comparativos según el tipo de catarata predominante siguiendo la clasificación LOCS III (Lens Opacity Cataract System): nuclear, cortical y subcapsular posterior (SCP). Resultados: Se evaluaron 78 ojos de 78 pacientes con edad promedio $69.3 \pm 9.6$ (51-84) años. En el preoperatorio, la sensibilidad al contraste bajo estuvo alterada levemente en el grupo nuclear y severamente en el grupo SCP. El puntaje de la escala limitaciones de la CVRV fue significativamente menor para el grupo SCP comparado con el grupo nuclear (0 [0-15.6 vs. 6.2 [0-12.5; $p=0.040$ ). Luego de la cirugía, la AVMC y la sensibilidad al contraste mejoraron en los tres grupos de estudio. Los cambios de mayor significancia

Date of reception: 05-07-2019 Date of acceptance: 07-11-2019
Available online: 01-03-2020 Rev Mex Oftalmol (Eng). 2020;94(2):57-64 www.rmo.com.mx \footnotetext{
DOI: 10.24875/RMOE.M20000103

E-mail: r_adrianzen@yahoo.com
}

2604-1731/@ 2019 Sociedad Mexicana de Oftalmología. Published by Permanyer. This is an open access article under the CC BY-NC-ND license (http://creativecommons.org/licenses/by-nc-nd/4.0/). 
se observaron en el grupo SCP. La mejoría en la CVRV se relacionó positivamente con la ganancia de agudeza visual en alto y bajo contraste en los tres grupos de estudio. Conclusion: La cirugía de catarata mejoró significativamente la sensibilidad al contraste y la calidad vida de todos los pacientes, especialmente en quienes presentaron opacidad SCP.

Palabras claves: Catarata. Agudeza visual. Calidad de vida. Sensibilidad de contraste. Facoemulsificación. Encuestas y cuestionarios.

\section{Introduction}

Visual impairment affects 285 million people worldwide, of which 39 million are blind and 246 million have low vision ${ }^{1}$. According to studies conducted by the World Health Organization, cataract is the most frequent cause of reversible blindness in the world. It mainly affects people living in developing countries and is responsible for $51 \%$ of global blindness, with about 20 million blind people ${ }^{2}$.

Impaired vision caused by the development of cataract occurs insidiously, progressively altering high-contrast visual acuity (VA), a standard measure of visual function ${ }^{3}$. However, patients may have a marked reduction in contrast sensitivity despite having only a slight to moderate loss of high-contrast VA, and show a reduced discriminatory ability to identify objects or discriminate colors under dim light conditions, or experience glare in indirect lighting conditions (e.g., sunny days or when a car is approaching with the lights on $)^{4,5}$. These alterations will occur to a lesser or greater degree depending on the severity and specific pattern of lenticular opacification, and will modify the quality of life of patients in different ways.

In most public hospitals, contrast sensitivity and quality of life tests are not routinely performed in cataract patients despite being easy to apply and inexpensive. Its implementation in ophthalmological care would complement the evaluation of the patient's visual function and allow to objectively identify candidates for a timely surgical procedure.

\section{Objective}

To determine the effect of cataract surgery on contrast sensitivity and quality of life in patients with different types of senile cataract.

\section{Methods}

\section{Design}

A prospective, pre-test/post-test design study was conducted in patients with three different types of cataracts, in whom best-corrected visual acuity (BCVA) was evaluated at various levels of contrast, as well as quality of life before and after cataract surgery.

\section{Population and sample}

The study was conducted between January 2 and July 31, 2017 at the Instituto Regional de Oftalmología Javier Servat Univazo in the city of Trujillo, Peru. The sample size was calculated using an analysis of variance (ANOVA), considering three study groups, an alpha risk of 0.05 , a beta risk of 0.10 , a minimum difference to be detected of 15 points in the total NEIVFQ-25 score gain (National Eye Institute Visual Function Questionnaire-25) ${ }^{6}$, with a standard deviation of 5 points and a $50 \%$ expected proportion of losses to follow-up. A sample of at least 7 patients in each group was obtained. Patients were selected through consecutive sampling during the study period. Patients included were older than 50 years, of both sexes, with a diagnosis of bilateral cataract and indication for phacoemulsification with intraocular lens implantation, with a preoperative BCVA equal to or worse than 20/200 and an axial length between 22.5 and $25 \mathrm{~mm}$. Patients with a history of intraocular surgery and with ocular and systemic comorbidities with an impact on their visual capacity, such as diabetic retinopathy, macular degeneration, glaucoma, etc., and those who had intraoperative and/or postoperative complications were excluded from the study. All patients signed an informed consent to participate in the study.

The study population was divided into three groups (nuclear, cortical and posterior subcapsular [PSC]), according to the predominant type of cataract of the eye with the lower BCVA. Lenticular severity staging was based on the LOCS III classification (Lens Opacity Cataract System $)^{7}$. Due to the difficulty in finding cases with exclusive cortical opacification and PSC cataract due to their low frequency, coexistence of nuclear opacification $<2$ was allowed for the conformation of these groups.

Before and after 30 days of the cataract surgery of the first eye, BCVA was evaluated in each patient at 
$100 \%, 25 \%, 10 \%, 5 \%, 2.5 \%$ and $1.25 \%$ of contrast level, as well as visual function and vision-related quality of life (VRQOL). These evaluations were performed by one of the researchers (VBD), who was not involved in the surgeries.

The surgeries were performed by three surgeons experts in cataract surgery (PCS, JHP and SCA) and in all of them a monofocal, foldable, one-piece and aspherical intraocular lens was implanted (Tecnis ZCB00, Abbott Medical Optics, Inc., Santa Ana, CA).

\section{High-contrast visual acuity}

BCVA at $100 \%$ contrast was evaluated at 4 meters with the logMAR ETDRS chart (Precision Vision, Inc., La Salle, IL), in an exam room under dim light conditions (161 lux). The height of the chart was standardized with a distance of $124.46 \mathrm{~cm}$ between the third row of letters and the floor. BCVA rating based on the number of letters read was converted to logMAR units according to the instructions provided by the Diabetic Retinopathy Clinical Research Network (available at: http://drcrnet.jaeb.org)

\section{Low-contrast visual acuity and contrast sensitivity curves}

BCVA at $1.25 \%, 2.5 \%, 5 \%, 10 \%$ and $25 \%$ contrast levels was evaluated at 3 meters with low-contrast LEA number charts (Good-Lite Company, Elgin, IL), under the same lighting conditions described for high-contrast BCVA. With the data obtained, pre- and postoperative contrast sensitivity curves were prepared for each type of cataract as proposed by the manufacturer (manual available at: https://www.good-lite.com).

\section{Visual function and vision-related quality of life}

The Spanish version of the NEI-VFQ- $25^{8}$ questionnaire was applied, which is composed of 12 scales: general health, general vision, mental health, eye pain, near vision, far vision, peripheral vision, social performance, color vision, driving, limitations and dependence. This instrument has been previously validated for use in Peru in patients undergoing cataract surgery 9 .

\section{Ethical aspects}

The study was governed by the ethical principles of the Declaration of Helsinki and was approved by the Institutional Research and Ethics Committee.
Table 1. Baseline demographic and clinical characteristics of patients with different types of cataract

\begin{tabular}{|c|c|c|c|}
\hline & $\begin{array}{l}\text { Nuclear } \\
n=32\end{array}$ & $\begin{array}{l}\text { Cortical } \\
n=10\end{array}$ & $\begin{array}{c}\text { SCP } \\
n=35\end{array}$ \\
\hline $\begin{array}{l}\text { Age (years) } \\
{[\text { mean + SD (R)] }}\end{array}$ & $\begin{array}{c}74.4 \pm 7.4 \\
(51-84)\end{array}$ & $\begin{array}{c}70.2 \pm 9.2 \\
(52-82)\end{array}$ & $\begin{array}{c}64.9 \pm 8.5^{*} \\
(51-82)\end{array}$ \\
\hline Sex M/F & $19 / 13$ & $6 / 4$ & $17 / 18$ \\
\hline Laterality OD/OS & $15 / 17$ & $4 / 6$ & $14 / 21$ \\
\hline $\begin{array}{l}\text { LOCS III } \\
\text { [mean + SD (R)] }\end{array}$ & $\begin{array}{c}2.7 \pm 0.6 \\
(2-4)\end{array}$ & $\begin{array}{c}3.6 \pm 0.8^{\dagger} \\
(2.5-5)\end{array}$ & $\begin{array}{c}3.9 \pm 0.6^{*} \\
(2.5-5)\end{array}$ \\
\hline
\end{tabular}

\section{Statistical analysis}

Statistical analysis was performed with the SPSS version 23 package (IBM Corporation Inc., Armonk, NY). Parametric and non-parametric statistics were used depending on data normality. For intergroup analysis we used the analysis of variance (one-factor ANOVA) and the Kruskal Wallis test with Dunn-Bonferroni adjustment. The postoperative change of the variables was evaluated with Wilcoxon signed-rank test. A correlation analysis was performed between the postoperative variation of the total NEI-VFQ 25 score and the variation of BCVA at different levels of contrast, calculating Spearman's Rho $(\rho)$ correlation coefficient. The differences were considered statistically significant when the $p$-value was $<0.05$.

\section{Results}

Eighty-two patients with cataracts met the inclusion and exclusion criteria. Three patients were lost during follow-up and 2 were eliminated due to persistence of corneal edema 30 days after surgery, so the final sample consisted of 77 patients (nuclear group $=32$, cortical group $=10$, posterior group $=35$ ). The demographic and clinical characteristics in each study group are shown in Table 1. The average age of the patients was $69.3 \pm 9.6(51-84)$ years. The PSC group included younger patients and presented a higher degree of opacity compared to the other two groups.

In the preoperative period, patients in the nuclear group read more optotypes than those with cortical and PSC cataract at all contrast levels. BCVA at 100\%, 25\% and $10 \%$ contrast levels was significantly lower in the PSC group compared to the nuclear group. Patients 
Table 2. Preoperative visual acuity (number of letters) at different contrast levels by cataract type

\begin{tabular}{|c|c|c|c|c|c|c|c|}
\hline \multicolumn{8}{|c|}{ Contrast } \\
\hline & $\begin{array}{c}\text { Nuclear } \\
\text { \#optotypes } \\
\text { Median (IOR) }\end{array}$ & $\begin{array}{l}\text { LogMAR } \\
\text { equiv }\end{array}$ & $\begin{array}{c}\text { Cortical } \\
\text { \#optotypes } \\
\text { Median (IOR) }\end{array}$ & $\begin{array}{c}\text { LogMAR } \\
\text { equiv }\end{array}$ & $\begin{array}{c}\text { Posterior } \\
\text { \#optotypes } \\
\text { Median (IOR) }\end{array}$ & $\begin{array}{c}\text { LogMAR } \\
\text { equiv }\end{array}$ & $\mathbf{p}^{*}$ \\
\hline $1.25 \%$ & $0(0-9)^{\dagger}$ & - & 0 & - & 0 & - & 0.495 \\
\hline $2.5 \%$ & $0(0-17)^{\dagger}$ & - & $0(0-10)^{\dagger}$ & - & $0(0-10)^{\dagger}$ & - & 0.611 \\
\hline $5 \%$ & $1.5(0-9)$ & - & $0(0-5.3)$ & - & $0(0-3)$ & - & 0.204 \\
\hline $10 \%$ & $14(9.5-20.3)$ & 0.8 & $9(4.8-14)$ & 0.9 & $6(0-12)$ & 1 & $0.001^{1}$ \\
\hline $25 \%$ & $24(18.3-29)$ & 0.6 & $16.5(7.5-24.8)$ & 0.8 & $10(5-22)$ & 0.9 & 0.000 \\
\hline $100 \%$ & $34(24-71.5)$ & 1.02 & $32(20-72)$ & 1.06 & $22(11-32)$ & 1.26 & 0.003 \\
\hline
\end{tabular}

IQR: Interquartile range.

${ }^{\dagger}$ Range.

${ }^{\ddagger}$ Kruskal-Wallis with Dunn-Bonferroni correction, $\mathrm{p}<0.05$ statistically significant. *Posterior Subcapsular-Nuclear comparison.

with nuclear cataract discriminated more optotypes at low contrast than those with cortical and PSC cataracts (Table 2, Figs. 1 A, B and C).

After cataract surgery, BCVA improved for all contrast levels in the three study groups. The greatest clinical and statistical significant BCVA changes were observed in the PSC group (Table 3), represented by a greater shift of the sensitivity curve to the right compared to the other groups (Fig. 1 C).

The overall pre-operative VFQ-25 score was of 44.3 (35.9-50.7), 46.1 (35.2-56.5) and 45 (38.5-51.7) for the nuclear, cortical and PSC groups, respectively $(p=0.670)$. Regarding VRQOL scales, the limitations scale score was significantly lower in the PSC group compared to the nuclear group (0 [0-15.6 vs. $6.2[0-12.5$; $p=0.040$ ). Scores on the other scales showed no differences between groups. After surgery, the overall VFQ-25 score increased 24.5 (14.3-31.5), 25.8 (14.4-30.3) and $24.5(14.2-31.7)(p=0.992)$ points in the nuclear, cortical and PSC groups, respectively. VRQOL scale score increased significantly in the three study groups, with the exception of driving and eye pain scales. The increase in the far vision scale score was significantly greater in the PSC group compared to the nuclear group $(p=0.023)$ (Table 4). The increase in the overall VFQ-25 score in the entire study population was significantly and positively correlated with the increase in BCVA at contrast levels of $2.5 \%, 10 \%, 25 \%$ and $100 \%$ (Table 5 ).

\section{Discussion}

The development of cataract not only induces changes in VA, but also alterations of other components of visual function such as contrast sensitivity and stereopsis. These alterations usually differ according to the type of cataract, and in certain cases they can manifest even from early stages of opacification ${ }^{10,11}$. In this study we evaluated patients with cataracts with a vision restricted to $<20 / 200(\log M A R=1)$. The opacification of the cortical and PSC groups was significantly higher than that of the nuclear group, according to this selection criterion. BCVA was markedly reduced in the PSC group for all contrast levels, a fact that explains the greater gain of BCVA after surgery. In this regard, it is known that posterior subcapsular cataracts cause a reduction in contrast sensitivity for low spatial frequencies, even before a considerable sclerosis of the lens nucleus or a frank reduction of high-contrast VA occurs ${ }^{12}$. For this reason it has been proposed that contrast sensitivity is a better indicator of visual impairment in early stage cataracts than $\mathrm{VA}^{10}$; however, its routine application in ophthalmological practice is still uncommon. A different situation is observed with nuclear cataracts, in which the ability to discriminate at low contrast decreases progressively as opacification increases, and is closely related to the reduction of high-contrast $\mathrm{VA}^{11}$.

In this study, the improvement in quality of life was related to an increase of VA evaluated at different contrast levels. Contrast sensitivity tests are useful to define the impact of cataracts on individual performance and to estimate an occupational risk related to poor discrimination of objects under dim light conditions. An example of the aforementioned is reported by Owsley, et al. ${ }^{13}$, who indicated that contrast sensitivity is a factor independent from VA that causes road accidents in patients with 


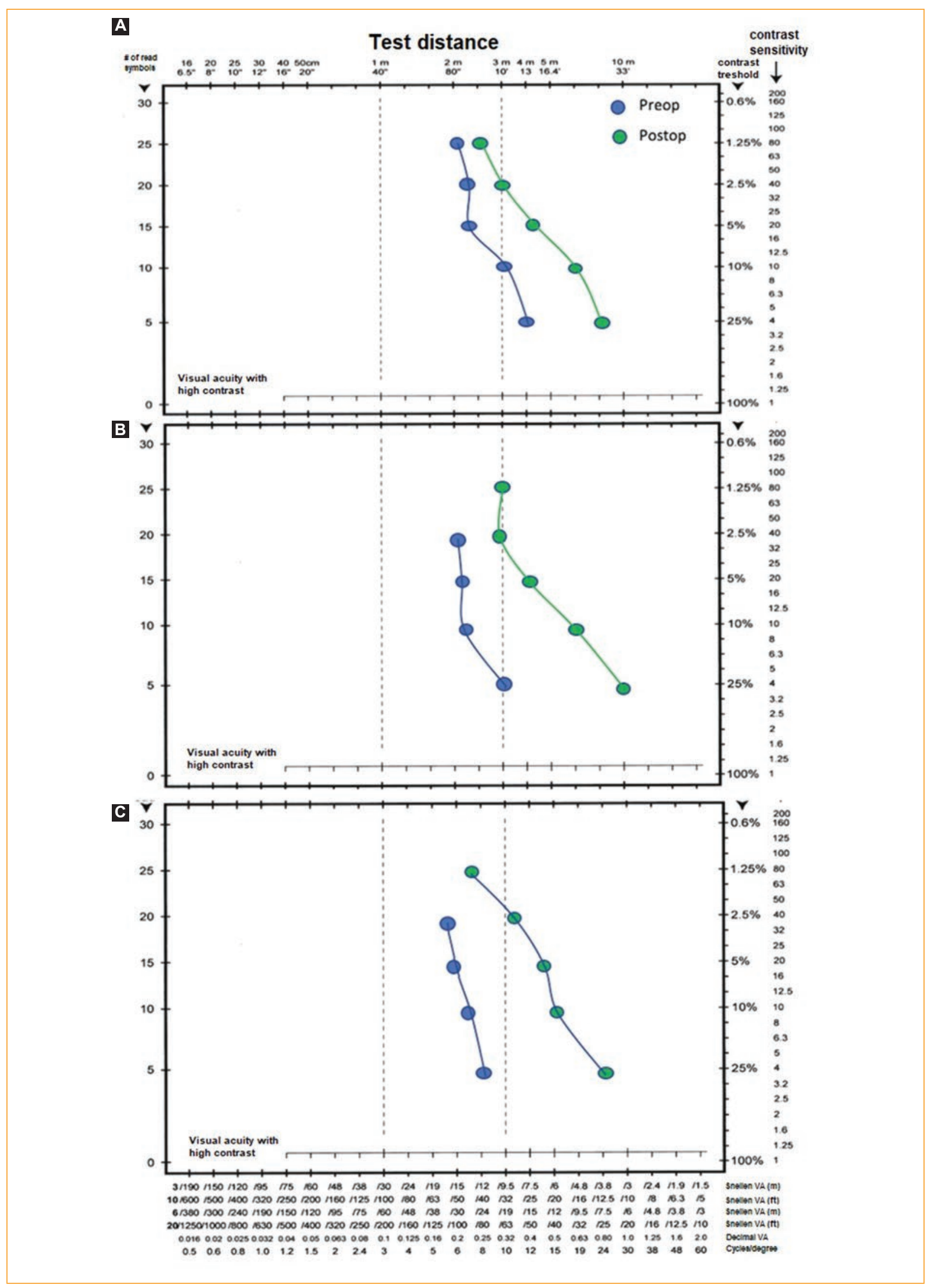

Figure 1. Pre- and post-operative contrast sensitivity curves in the nuclear A: cortical B: and posterior subcapsular C: groups. 
Table 3. Visual acuity at different pre- and post-operative contrast levels according to cataract type

\begin{tabular}{|c|c|c|c|c|c|c|}
\hline \multicolumn{7}{|c|}{ Contrast } \\
\hline \multirow{2}{*}{$\begin{array}{c}\text { Cataract } \\
\text { type }\end{array}$} & \multicolumn{2}{|c|}{ Preoperative } & \multicolumn{4}{|c|}{ Postoperative } \\
\hline & $\mathrm{N}^{0}$ patients & $\begin{array}{l}\text { BCVA \# letters Median } \\
\text { (IOR) }\end{array}$ & $\mathrm{N}^{0}$ patients & $\begin{array}{l}\text { BCVA \# letters Median } \\
\text { (IOR) }\end{array}$ & $\begin{array}{l}\text { BCVA gain } \\
(\%)\end{array}$ & $\mathbf{p}^{*}$ \\
\hline \multicolumn{7}{|c|}{ Nuclear ( $=32$ ) } \\
\hline $1.25 \%$ & 1 & $0(0-9)^{\dagger}$ & 13 & $0(0-10)$ & 13 & $0.001^{\ddagger}$ \\
\hline $2.5 \%$ & 4 & $0(0-17)^{\dagger}$ & 19 & $13.5(0-20)$ & 19 & $0.000^{\ddagger}$ \\
\hline $5 \%$ & 16 & $1.5(0-9)$ & 28 & $26(11.8-33.8)$ & 24.5 & $0.000^{\ddagger}$ \\
\hline $10 \%$ & 30 & $14(9.5-20.3)$ & 30 & $34(20.8-38.8)$ & $20(142 \%)$ & $0.000^{\ddagger}$ \\
\hline $25 \%$ & 32 & 24 (18.3-29) & 32 & $44(29.3-49.8)$ & $20(83 \%)$ & $0.000^{\ddagger}$ \\
\hline $100 \%$ & 32 & $34(24-71.5)$ & 32 & $82(73.3-82)$ & $48(141 \%)$ & $0.000^{\ddagger}$ \\
\hline \multicolumn{7}{|c|}{ Cortical $(n=10)$} \\
\hline $1.25 \%$ & 0 & 0 & 1 & $0(0-19)^{\dagger}$ & 0 & 0.317 \\
\hline $2.5 \%$ & 1 & $0(0-10)^{\dagger}$ & 7 & $5.5(0-22.5)$ & 5.5 & $0.018^{\ddagger}$ \\
\hline $5 \%$ & 3 & $0(0-5.3)$ & 10 & $23(9-35.3)$ & 23 & $0.008^{\ddagger}$ \\
\hline $10 \%$ & 9 & $9(4.8-14)$ & 10 & $36(19.5-46$ & $27(300 \%)$ & $0.005^{\ddagger}$ \\
\hline $25 \%$ & 9 & $16.5(7.5-24.8)$ & 10 & $44(30.8-53.8)$ & $27.5(167 \%)$ & $0.005^{\ddagger}$ \\
\hline $100 \%$ & 10 & $32(20-72)$ & 10 & 79.5 (74.5-82) & $47.5(148 \%)$ & $0.005^{\ddagger}$ \\
\hline \multicolumn{7}{|c|}{ Posterior subcapsular ( $\mathrm{n}=35$ ) } \\
\hline $1.25 \%$ & 0 & 0 & 13 & $0(0-8)$ & 0 & $0.001^{\ddagger}$ \\
\hline $2.5 \%$ & 2 & $0(0-10)^{\dagger}$ & 22 & $14(0-22)$ & 14 & $0.000^{\ddagger}$ \\
\hline $5 \%$ & 11 & $0(0-3)$ & 27 & $25(4-32)$ & 25 & $0.000^{\ddagger}$ \\
\hline $10 \%$ & 24 & $6(0-12)$ & 35 & $28(16-38)$ & $22(366 \%)$ & $0.000^{\ddagger}$ \\
\hline $25 \%$ & 33 & $10(5-22)$ & 35 & $44(23-52)$ & $34(340 \%)$ & $0.000^{\ddagger}$ \\
\hline $100 \%$ & 35 & $22(11-32)$ & 35 & $77(72-82)$ & $55(250 \%)$ & $0.000^{\ddagger}$ \\
\hline
\end{tabular}

IQR: Interquartile range.

${ }^{\dagger}$ Range.

${ }^{t}$ Wilcoxon signed-rank test

${ }^{*} p<0.05$ statistically significant.

cataract, highlighting the importance of its evaluation in therapeutic decision making. Contrast sensitivity, therefore, should be considered in daily ophthalmological practice as a more sensitive indicator of impaired visual function compared to VA in patients with cataract.

Regarding VRQOL evaluation scales, we observed that patients with PSC cataract showed greater limitations to perform daily life activities, probably due, in part, to the significant deterioration of contrast sensitivity. Other studies have reported that VRQOL in patients with cataract is more closely related to changes in contrast sensitivity and stereopsis than to VA changes ${ }^{1,6,14,15}$.
After surgery, we observed a significant increase in most of the VFQ-25 scales in each of the cataract subtypes. This improvement in visual function was statistically superior for the PSC group compared to the nuclear group for the far vision scale. This difference not observed in the preoperative period could be explained not only by the gain of high-contrast BCVA, but also by the significant improvement in contrast sensitivity observed in the PSC group. However, it is necessary to highlight that the change in quality of life depends on several factors, including age, physical and emotional health, cognitive status, the influence 
Table 4. Postoperative score variation of vision-related quality of life scales evaluated with VF0-25 by cataract type

\begin{tabular}{|c|c|c|c|c|}
\hline \multicolumn{5}{|c|}{ Post-preoperative variation } \\
\hline VF0-25 & Nuclear Median (IOR) & Cortical Median (IOR) & PSC Median (IOR) & ${ }^{*} p$ \\
\hline GH & $25(25-25)$ & $25(0-25)$ & $25(0-25)$ & 0.789 \\
\hline GV & $20(20-40)$ & $20(20-20)$ & $20(20-40)$ & 0.519 \\
\hline $\mathrm{MH}$ & $31.3(18-37)$ & $28.1(12.5-39.1)$ & $25(12.5-37.5)$ & 0.923 \\
\hline OP & $0(-12.5-21.9)$ & $6.3(-15.6-12.5)$ & $-12.5(0-12.5)$ & 0.979 \\
\hline NV & $33(18.8-41.7)$ & $33.3(25-43.8)$ & $33.3(25-41.7)$ & 0.529 \\
\hline FV & $33(10.4-41.7)$ & $33.3(6.3-41.7)$ & $33.3(8.3-41.7)$ & $0.023^{\dagger}$ \\
\hline PV & $25(0-25)$ & $25(0-25)$ & $25(0-50)$ & 0.959 \\
\hline SP & $25(0-50)$ & $25(-12.5-37.5)$ & $0(-25-50)$ & 0.762 \\
\hline Cov & $25(0-43.8)$ & $25(18.8-50)$ & $25(0-50)$ & 0.732 \\
\hline D & $0(0-3.1)$ & $0(0-1)$ & $0(0-8.3)$ & 0.980 \\
\hline $\mathrm{L}$ & $37.5(37.5-50)$ & $50(37.5-65.6)$ & $37.5(37.5-62.5)$ & 0.383 \\
\hline $\mathrm{De}$ & $16.7(0-33.3)$ & $20(16.7-33.3)$ & $25(8.3-33.3)$ & 0.648 \\
\hline Total & $24.6(14.3-31.5)$ & $25.8(14.4-30.3)$ & $24.5(14.2-31.7)$ & 0.992 \\
\hline
\end{tabular}

GH: General health; GV: General vision, MH: Mental health; OP: Ocular pain; NV: Near vision; FV: Far vision; PV: Peripheral vision; SP: Social performance; CoV: Color vision; D: Driving; L: Limitations; De: Dependence; IQR: Interquartile range; VFO-25: Visual Function Questionnaire-25.

${ }^{\dagger} K$ ruskal-Wallis with Dunn-Bonferroni correction, $\mathrm{p}<0.05$ statistically significant.

*Posterior Subcapsular-Nuclear comparison.

Table 5. Correlation between the variation of the total NEI-VFO 25 score and postoperative high- and lowcontrast BCVA variation

\begin{tabular}{|l|c|c|}
\hline$\triangle$ Total NEI-VF0-25 score & Rho coefficient $(\Delta)$ & p-value \\
\hline$\triangle$ BCVA 1.25\% & 0.2 & 0.109 \\
\hline$\triangle$ BCVA 2.5\% & 0.3 & 0.009 \\
\hline$\triangle$ BCVA 5\% & 0.2 & 0.114 \\
\hline$\triangle$ BCVA 10\% & 0.3 & 0.006 \\
\hline$\triangle$ BCVA 25\% & 0.3 & 0.007 \\
\hline$\triangle$ BCVA 100\% & 0.5 & 0.000 \\
\hline
\end{tabular}

Spearman's correlation, $p<0.05$, statistically significant.

BCVA: best-corrected visual acuity; NEI-VFQ-25: National Eye Institute-Visual Function Questionnaire-25.

of other comorbidities and the patient's social environment. In this sense, the VFQ-25 not only evaluates the limitations to perform tasks that depend on visual health, but also the mental health and social performance of the individual, which makes it a better indicator of visual performance satisfaction than $\mathrm{VA}^{14}$. Similar results to ours were reported by To, et al. ${ }^{6}$ and Ishii, et al. ${ }^{16}$, who also pointed out that the improvement in postoperative VRQOL is closely related to the improvement of the cognitive and depressive status of the patients. On the other hand, since the VFQ-25 was a questionnaire not specific for the type of condition, the pain scale did not show a significant variation, since cataract surgery does not involve a serious aggression to the eye, and it is a procedure with a fast recovery with minimal discomfort ${ }^{9,17}$. Likewise, the driving scale score did not show a relevant change after surgery, since our study population usually do not drive, due to limitations such as age, socioeconomic status and educational level of the patients treated in our institution.

Our study has some limitations, like a potential measurement bias generated by the VA and VRQOL evaluator, since he was a researcher and, therefore, was not blinded to the study. On the other hand, due to the low frequency of cataracts with cortical predominance, sampling during the study period allowed the inclusion of only 10 patients in this group. In the future, the inclusion of patients with nuclear-cortical and cortical-posterior opacity could be considered to indirectly assess the effect of cortical opacity on the evaluation parameters. Our results only report the benefits of cataract monocular surgery on contrast sensitivity and VRQOL. A complement to these 
results would be the evaluation of the effects of bilateral cataract surgery, which has shown in other studies to induce additional benefits in the visual function of patients ${ }^{6,18}$.

The approach of the patient with cataract should be carried out comprehensively, considering both clinical aspects and visual function in real-world activities. A marked limitation of the ability to perform usual daily activities as a result of vision impairment, would be an indication for an early surgical approach. On the other hand, difficulties in the application of visual function questionnaires must be considered to implement questionnaires specific to the pathology evaluated, considering the socio-cultural variants of the populations.

Due to its implications in decision-making, we recommend including contrast sensitivity and vision-related quality of life evaluations in the routine examination of patients with cataract, as they provide more information on the disability of patients in their daily activities.

\section{Conclusions}

In this study, cataract surgery significantly improved high- and low-contrast VA and quality of life in all patients evaluated.

Patients with posterior subcapsular cataract had lower contrast sensitivity and greater limitation to perform activities as a result of visual impairment compared to patients with nuclear cataracts.

The postoperative improvement of VA and contrast sensitivity was substantially higher in patients with PSC cataract, as well as their perception of improvement in the performance of activities using far vision. Quality of life questionnaires such as VFQ-25 must be culturally adapted in order to administer them objectively in our population.

\section{Conflicts of interest}

The authors declare no conflicts of interest.

\section{Funding}

The authors received no specific funding for this work.

\section{Ethical disclosures}

Protection of human and animal subjects. The authors declare that no experiments were performed on humans or animals for this study.

Confidentiality of data. The authors declare that no patient data appear in this article.

Right to privacy and informed consent. The authors declare that no patient data appear in this article.

\section{References}

1. Acosta R, Hoffmeister L, Román R, Comas M, Castilla M, Castells X. Revisión sistemática de estudios poblacionales de prevalencia de catarata. Arch Soc Esp Oftalmol. 2006;81(9):509-16.

2. WHO I Priority eye diseases [Internet]. WHO. Disponible en: http://www. who.int/blindness/causes/priority/en/

3. Kessel L, Andresen J, Erngaard D, Flesner P, Tendal B, Hjortdal J. Indication for cataract surgery. Do we have evidence of who will benefit from surgery? A systematic review and meta-analysis. Acta Ophthalmol (Copenh). 2016;94(1):10-20.

4. Sniatecki JJ, Styles C, Boyle N, Sanders R. Cataract surgery: factors influencing decision to treat and implications for training (south-east Scotland 2008-2014). Clin Ophthalmol AuckI NZ. 2015;9:1821-7.

5. Ginsburg AP. Contrast sensitivity: determining the visual quality and function of cataract, intraocular lenses and refractive surgery. Curr Opin Ophthalmol. 2006;17(1):19.

6. To KG, Meuleners LB, Fraser ML, Do DV, Duong DV, Huynh V-AN, et al. The impact of cataract surgery on vision-related quality of life for bilateral cataract patients in Ho Chi Minh City, Vietnam: a prospective study. Health Qual Life Outcomes. 2014;12:16.

7. Chylack LT, Wolfe JK, Singer DM, Leske MC, Bullimore MA, Bailey IL, et al. The Lens Opacities Classification System III. Arch Ophthalmol. 1993;111(6):831-6.

8. Mangione CM, Lee PP, Gutierrez PR, Spritzer K, Berry S, Hays RD. Development of the 25-list-item National Eye Institute Visual Function Questionnaire. Arch Ophthalmol. 2001;119(7):1050-8.

9. Luján Paredes S, Pizango Malqui O, Alburquerque Duglio $M$, Valenzuela Tito M, Mayta-Tristán P. Variación de la función visual y calidad de vida luego de cirugía de catarata por facoemulsificación con implante de lente intraocular. Rev Mex Oftalmol. 2014;88(4):176-81.

10. Elliott DB, Situ P. Visual acuity versus letter contrast sensitivity in early cataract. Vision Res. 1998;38(13):2047-52.

11. Stifter E, Sacu S, Thaler A, Weghaupt H. Contrast acuity in cataracts of different morphology and association to self-reported visual function. Invest Ophthalmol Vis Sci. 2006;47(12):5412-22

12. Cheng CY, Yen MY, Chen SJ, Kao SC, Hsu WM, Liu JH. Visual acuity and contrast sensitivity in different types of posterior capsule opacification. J Cataract Refract Surg. 2001;27(7):1055-60.

13. Owsley C, Stalvey BT, Wells J, Sloane ME, McGwin G. Visual risk factors for crash involvement in older drivers with cataract. Arch Ophthalmol Chic III 1960. 2001;119(6):881-7.

14. Stifter E, Sacu S, Weghaupt $H$. Functional vision with cataracts of different morphologies: comparative study. J Cataract Refract Surg. 2004; 30(9):1883-91.

15. Datta S, Foss AJE, Grainge MJ, Gregson RM, Zaman A, Masud T, et al. The importance of acuity, stereopsis, and contrast sensitivity for health-related quality of life in elderly women with cataracts. Invest Ophthalmol Vis Sci. 2008;49(1):1-6.

16. Ishii K, Kabata T, Oshika T. The impact of cataract surgery on cognitive impairment and depressive mental status in elderly patients. Am J Ophthalmol. 2008;146(3):404-9.

17. Cabezas-León M, Gracia-San Román J, García-Caballero J, Morente-Matas P. Calidad de vida en pacientes intervenidos de catarata. Arch Soc Esp Oftalmol. 2005;80(8):449-56.

18. Castells X, Comas M, Alonso J, Espallargues M, Martínez V, García-Arumí J, et al. In a randomized controlled trial, cataract surgery in both eyes increased benefits compared to surgery in one eye only. J Clin Epidemiol. 2006;59(2):201-7. 